\title{
Carrying Jeremy Safran into sessions: relying on internal representations of researchers to facilitate emotion regulation, clinical intervention, and self-efficacy
}

\author{
Cheri L. Marmarosh, Chiara Abbatelli, Molly Tulipan, Jasmine Kaleka, Jordan Ohanesian, Charlotte Howson \\ Department of Psychology, The George Washington University, Washington, USA
}

\begin{abstract}
Relying on positive internal representations facilitates our ability to feel safe and secure when taking risks and provides a road map to guide us during interpersonal exchanges. Although most graduate programs encourage students to engage in research, we rarely link participating in research as directly influencing positive internal representations that can influence treatment. We used a qualitative method to examine how watching videos of Jeremy Safran, coding therapy sessions using his model, and reading his articles on ruptures and repairs influenced students' ability to self-soothe, take risks, and engage when patients confront them or withdraw. Results revealed that students often thought of Jeremy Safran and his colleagues during a session and recalled how he addressed ruptures in the videos they watched. When they were anxious during a session, they reported relying on the video coding training to facilitate emotion regulation during sessions. Having the research experience increased their clinical skills and overall clinical self-efficacy. Implications of our findings and future recommendations are discussed.
\end{abstract}

Key words: Internalization; Impact of psychotherapy research.

\section{Introduction}

Recalling positive memories and experiences of important caregivers to soothe our anxieties or guide us during uncertain times is one of the most adaptive aspects of

Correspondence: Cheri L. Marmarosh, Department of Psychology, The George Washington University, 1922 F Street, Washington D.C., USA.

E-mail: cmarmarosh@gmail.com

Citation: Marmarosh, C. L., Abbatelli, C., Tulipan, M., Kaleka, J., Ohanesian, J., \& Howson, C. (2019). Carrying Jeremy Safran into sessions: relying on internal representations of researchers to facilitate emotion regulation, clinical intervention, and self-efficacy. Research in Psychotherapy: Psychopathology, Process and Outcome, 22(1), 29-33. doi: 10.4081/ripppo.2019.371

Contributions: the authors contributed equally.

Conflict of interest: the authors declare no potential conflict of interest.

Funding: none.

Received for publication: 15 January 2019.

Revision received: 19 February 2019.

Accepted for publication: 21 February 2019.

This work is licensed under a Creative Commons Attribution NonCommercial 4.0 License (CC BY-NC 4.0).

CCopyright C.L. Marmarosh et al., 2019

Licensee PAGEPress, Italy

Research in Psychotherapy:

Psychopathology, Process and Outcome 2019; 22:29-33

doi:10.4081/ripppo.2019.371 human coping. Within the field of psychoanalysis, many theories have evolved around the notion that taking in and carrying internal representations of significant others promotes wellbeing and healthy development of the self (Bowlby, 1969; Freud, 1963; Loewald, 1962; Meissner, 1981; Winnicott, 1965). According to Geller (1987) internalizing another includes complex processes such as introjection and identification. Introjection constructs the emotionally charged representations of the self with others while identification facilitates the changes in self-representations when the self is modeled unconsciously after another. From their perspective, identification is "a second, occasional, more extended stage of internalization" that follows introjection (Orlinsky, Geller, Tarragona, \& Farber, 1993, p. 597). Geller and Farber (1993) argue that identification and introjection are all components of internalization because they describe how mental representations are encoded, retrieved, and revised. For the purpose of this paper, we will use the term internalization to include the process of introjection and identification.

The value of internalizing early caregivers has expanded from childhood to internalizing significant others later in life such as adult partners (Hazan \& Shaver, 1987), therapists (Geller \& Farber, 1993), and supervisors (Knox, 2003; Watkins, 2018). There is a growing literature examining how developing clinicians rely on their supervisors when navigating therapy sessions (Watkins, 2018), and we expect that supervisees will rely on their supervisors during clinical sessions to help their patients. Although we encourage our graduate students to participate in research, we rarely consider how interacting with researchers enhances 
their clinical skills and therapy sessions as well. The current paper will address how a group of first-year graduate students who spent a year learning the empirical support for repairing ruptures (Safran, Muran, \& Eubanks-Carter, 2011) and how to code ruptures (Eubanks-Carter, Muran, \& Safran, 2009) had unexpected benefits from the process. During two semesters of training, the students watched multiple videos of Jeremy Safran and his colleagues demonstrate different types of ruptures and repairs. This paper will explore how observing the researchers influenced their work with their first patients.

\section{Internalization of the therapist}

Geller and Farber (1993) were the first to empirically examine patient internalization and describe how patients' representations of therapists were retrieved when they experienced painful feelings such as sadness, anxiety, depression, fear, or loss. They found that patients experienced the felt presence of their therapists when they were trying to resolve a conflict or when working on problems discussed in therapy. More interestingly, they found that twenty percent of their sample were therapists themselves, and they revealed that they relied on representations of their own therapists when conducting therapy with others. In essence, therapists kept their therapist in mind when they were helping their patients. These internal representations were adaptive and functioned to facilitate emotion regulation during times in sessions when strong emotions surfaced and facilitated effective coping. Geller and Farber (1993) describe how relying on a calming and soothing image of one's therapist appeared to lessen the negative consequences of a self-deprecating self-image or painful feelings.

\section{Internalization of the supervisor}

Just as patients' internal representations of their therapist can play an important role in the treatment process, supervisees' internal representations of their supervisor can have an important role in the treatment process. Knox (2003) studied supervisees' internal representations of supervisors and found that supervisees retrieved the supervisors' manner of relating when they had moments of uncertainty or when they needed positive reinforcement to be helpful to their patients. Knox, Caperton, Phelps, and Pruitt (2014) found that supervisees recalled soothing and reassuring images of the supervisor, reminded themselves of what the supervisor said, repeated things that the supervisor expressed in supervision, and even copied the supervisors' style during treatment. Geller, Farber, and Schaffer (2010) note that internal images of supervisors can occur visually, auditory, felt, or combined and influence the therapists' clinical work and overall development.

\section{Internalization of the researcher}

Although there has been much written about the benefits of graduate students participating in research, we could not find one study that examined how participating in psychotherapy research made a graduate student a more confident and skillful therapist when treating a patient. We could not find any study examining how therapists carried their research advisors into therapy sessions. In addition, we could not find anything on how being trained to code therapy sessions and then actually coding sessions for research provides students with internal representations of researchers/therapists who model interventions that facilitate effective treatment and emotion regulation during stressful interactions.

We discovered the benefits of participating in psychotherapy research when we applied Eubanks-Carter et al.'s (2009) 3RS Coding Model to examine ruptures and repairs in our training clinic. We were studying the psychotherapy relationship and how therapist/patient attachment styles influence treatment. My students and I learned the 3RS coding system, a coding system that is designed to identify ruptures and repairs in the therapy sessions. The training focuses on identifying two different kinds of client ruptures, withdrawal and confrontational, and then identifying what things therapists do after a rupture to facilitate repairs such as empathize, explain, or ask questions. In order to learn the system, one has to become familiar with the theoretical model, watch videos of Safran, Muran, and Eubanks-Carter demonstrating the different types of ruptures and the interventions that follow, and then watch many videos of sessions to ensure reliability among coders. This process forces students to immerse themselves in therapy sessions where patients are angry with the therapist or withdrawn and detached. They watch multiple videos looking at how patients challenge the validity of the treatment or the usefulness of the therapy. They also watch multiple videos of patients becoming silent or passive aggressive in session. They do all of this during the first year of their graduate training when they are on my research team and before they see patients in the Clinic.

At the start of the second year of graduate school, students take my supportive therapy course and start seeing patients in the clinic. I noticed that the students on the research team were less overwhelmed and more confident in what to do and were more curious and empathic when they did role plays in my class. I informally asked them what was guiding them in the role plays, and they revealed something I was not expecting to hear. They all described ways that they recalled the videos of Jeremy Safran and his colleagues, and the coding system which gave them options to rely on when encountering stressful moments in the sessions. The two main things they said were i) that they often recalled the videos to model what to say and do and ii) that they relied on the coding system to consider alternative interventions. Much like supervisees internalizing their supervisors, the students said they recalled Jeremy Safran and how he handled the patient who was experiencing a rupture. They revealed retrieving his image with the patients to i) regulate their level of distress when 
facing patients' confrontations, ii) assist them in what to do to facilitate a repair, and iii) help them feel more confident that they are not "bad" therapists and absorb the patients' blame and disappointment in them. They also revealed that having the coding system for repairs helped them consider multiple options to intervene (i.e. being curious, explaining the rationale of the treatment, or empathizing with the patient) and they felt more confident knowing they could try different things to facilitate repairs. Most importantly, they felt that these challenging moments happen in all therapy relationships, even with the best therapists, and it did not mean that they were not going to be good therapists. One example of this is when a research student said:

As a new therapist, it is difficult to hear your worst fears confirmed: that you are ineffectual, unhelpful, and even damaging to the patient. My ability to stay with the patient during a moment when a patient is challenging me rather than become defensive or tongue-tied can be directly attributed to my work with the 3RS coding system. Through this work, I learned that ruptures are a natural and inevitable part of therapy; successfully repairing a rupture can further the work of therapy and deepen the relationship. Dr. Safran's work on ruptures and repairs directly influenced my ability to stay present with the patient, work through a difficult moment, and feel confident in my capacity to reconnect with the patient after painful moments of disconnection.

\section{Regulating therapist emotions in order to empathize with patients}

As this therapist states, being a new therapist is challenging. Seeing patients for the first time is often stressful for beginning clinicians, especially if they feel pressured to do well, are being videotaped for supervision, and are treating patients in a training clinic who have more therapy experience than they do. Many of the patients in our training clinic transfer from prior therapists, and they come to treatment with years of therapy experience and complex mental health issues. The mere thought of inviting patients to share their honest feelings of disappointment and anger with them is anxiety provoking. Without the extensive practice-based training and research experience that empirically validates the benefits of helping patients share their negative reactions toward them, most novice clinicians would shy away from going there. However, if the therapist has watched and coded videos of therapists successfully navigating these reactions, they have seen how inviting conflict into the relationship can be critical to the relationship, and they have a model of what to do and how to do it.

One research student described her experience with a client and how participating in research impacted her ability to stay calm and empathize with the patient.
One day, my patient walked into the consulting room and said, "I don't know what therapy is doing for me. Talking about my [trauma] makes me feel terrible. Every time I leave therapy, I either feel worse or completely the same." My patient was expressing complaints and concerns about me as the therapist. Though her comments were jarring, anxiety-provoking, and tugged at my insecurities as a new therapist, I knew immediately that this was a confrontational rupture. I then imagined the video of Jeremy Safran and modeled my intervention after him. I shared my appreciation for her honesty and commended her on her bravery for doing so. I then empathized with her feelings of frustration with me and her feelings of helplessness and hopelessness. I also recalled a video when Dr. Eubanks-Carter acknowledged her part in the rupture and I decided to acknowledge my contribution to my patient's feelings. This represented a large step forward in the treatment and ultimately served to strength our therapeutic alliance.

\section{Internalizing researchers: facilitating curiosity and protecting from self-blame}

In addition to empathizing with the patient, it is critical for therapists to help patients explore reactions and protect themselves from excessive self-blame or worse, blaming the patient. When therapists are able to manage their own emotions, they can be curious and wonder how their patients feel without placing fault on anyone. One student stated:

Recognizing that a rupture had occurred allowed me to then access repair strategies that I had learned from my experience watching the videos. I had to begin to repair the relationship by acknowledging my empathic failure and providing a space for a discussion of what that was like for the patient. I had to remain calm and focus on what the patient was feeling even though the patient was angry and attacking me. I remember the image of Jeremy Safran, and I tried to take on his tone of voice as I explored how my patient was feeling. It was not easy because I felt guilty and wondered if I was good enough to help this patient. I have a tendency to blame myself first and the training helped me stop that. Seeing patients challenge Jeremy Safran made me realize that it may be less about my abilities. I could see that maybe it can be about the patient and our relationship.

\section{Internalizing the researcher: knowing what to do}

Having a clear vision or road map of what to do when a client is frustrated or avoiding something in the treatment helps developing therapists engage in the treatment process. For example, one research student described her 
first rupture with a patient and how the research helped her navigate it.

I noticed Ms. E wearing an expression that was previously unfamiliar to me. After I made an interpretation, she frowned and appeared agitated. The session continued, but I noticed Ms. E detach and withdraw from the work in a manner that was inconsistent with her prior sessions. As we sat in silence, the video with Jeremy Safran and his patient came to mind. It dawned on me that Ms. E and I were experiencing our first rupture; I had made an interpretation that did not land with her, and she withdrew. I was able to notice this process as it occurred in the here and now and imagine what Jeremy Safran would do in this situation. I recalled Jeremy sharing his observations with the client, so I decided to do the same. I acknowledged our moment of mis-attunement. My client responded well to my ability to recognize her reaction, and we began to repair the rupture. I likely would not have been able to intervene in this manner had I not engaged in research that helped me identify ruptures and repairs as they occur. Through engaging in this research, I was also able to regulate my own distress in the moment, as I was aware of the rupture that was unfolding between us.

Another student on the research team said something similar. She noted that she observed a rupture with her first patient and felt guilty about her contribution. Despite her self-blame, she described how her research experience facilitated her ability to respond.

I did not panic. I had seen many ruptures during my training, and I knew how to identify them and how to work in the direction of repair. I was aware of how frequently they occur in therapy, and I was hopeful that, by acknowledging and speaking about the episode, I could create the necessary space to explore and work on the rupture. Although the patient did not show up for two sessions, I did not give up and I was able to convince her to come in to discuss what had happened.

\section{Discussion and Conclusions}

This paper highlights the positive impact that researchers can have on graduate student clinical training. We found that learning about ruptures, repairs, and the therapy alliance had a significant impact on novice clinicians and their therapy treatment. It is not surprising that coding sessions and watching videos of therapy sessions would influence clinical work. However, it was not apparent how important the internal representation of experts like Jeremy Safran would be to soothe anxiety, foster modeling, and alleviate self/other-blame. When I asked my students what was the most helpful, the video or coding sessions, they all said the videos. All of them internalized the tone of voice, openness, and non-defensive posture that Jeremy Safran and his colleagues demonstrated. More importantly, they observed the effectiveness of how this approach moved the patient from anger/hurt to more trust and self-disclosure. My students spoke about how reading about therapy is one thing, but seeing it done effectively is another. We know it is important to have an evidence-based theoretical model, but it may be even more important to teach the approach with live or taped sessions of experts doing the treatment. The students on my research team had an advantage over the students in my course who had never seen a therapy session or worse had been in ineffective therapy themselves.

This paper was not designed to be a strong qualitative investigation of internalization but rather a paper honoring Jeremy Safran; there are many limitations to interpreting the findings. We clearly have a small and biased sample. I spoke informally with my graduate research team members and they likely felt pressed to say positive things about the impact of research. We did not implement a more sophisticated interview that would tap into the many components of internalization or base our investigation on prior studies using a strong methodology. Despite these important limitations, we do believe that it is important for future researchers to study how participating in applied research can directly enhance clinical work.

In the future, it would be important to study how live demonstrations influence therapists' ability to engage in challenging clinical experiences. We know that providing more training on the therapy relationship is useful (Hilsenroth, Ackerman, Clemence, Strassle, \& Handler, 2002). For example, I believe it would be very useful for developing clinicians to receive training and watch effective conversations about micro-aggressions, race, class, gender, sexual orientation, trauma, or anything frightening or emotionally triggering for them. Having observations of experts who are effective can facilitate emotion regulation and the ability to engage in more productive ways. These observations may not be internalizations, but that is an important question that needs to be studied. According to Watkins (2018), representations tend to develop through a number of meaningful interactions over time. It is possible that students can identify with experienced clinicians and the identification serves a similar purpose as internalization.

We know that carrying the memory of someone can be an important aspect of grief and mourning. Those studying psychotherapy termination argue that internalizing the therapist is one of the important signs that the treatment has been effective and patients may be ready to say goodbye (Arnold, Farber, \& Geller, 2000). According to Loewald (1988), mourning involves the "gradual relinquishment of a cherished relationship with another person and its internalization" (p. 156). There is a letting go of the relationship 
one has with the external object and a transformation of that external object to one that is held within. In many ways, termination and internalization are interconnected because, in order to say goodbye, one creates an internal object that remains. Jeremy Safran is no longer with us, but his research and desire to move the field of psychotherapy forward has changed my students who are comforted by him in moments of distress. His manner, wisdom, compassion, openness, and curiosity has enabled them to feel excited, hopeful, and engaged in the work even when it is uncomfortable, frightening, and challenging.

\section{References}

Arnold, E. G., Farber, B.A., \& Geller, J. D. (2000). Changes in patients' self-representation over the course of psychotherapy. The Journal of the American Academy of Psychoanalysis, 28, 449-466.

Bowlby, J. (1969). Attachment and loss. Vol. 1: Attachment. New York: Basic Books.

Eubanks-Carter, C., Muran, J. C., \& Safran, J. D. (2009). Rupture resolution rating system (3RS): Manual. New York: Beth Israel Medical Center.

Freud, S. (1963). Analysis terminable and interminable. In P. Rieff (Ed.) \& J. Riviere (Trans.), Therapy and Technique (pp. 233-271). New York: Collier Books, Macmillan Publishing Company. (Original work published 1937).

Geller, J. D. (1987). The process of psychotherapy: Separation and the complex interplay among empathy, insight and internalization. In J. Bloom-Feshbach \& S. Bloom- Feshbach (Eds.), The psychology of separation through the life-span. San Francisco: Jossey-Bass.

Geller, J. D., \& Farber, B. A (1993). Factors influencing the process of internalization in psychotherapy. Psychotherapy Research, 3, 166-180.

Geller, J.D. Farber, B. A., \& Schaffer, C. E. (2010) Representa- tions of the supervisory dialogue and the development of psychotherapists. Psychotherapy, 47, 211-220.

Hazan, C., \& Shaver P. (1987). Romantic love conceptualized as an attachment process. Journal of Personality and Social Psychology, 53, 511-524.

Hilsenroth, M., Ackerman, S., Clemence, A., Strassle, C., \& Handler, L. (2002). Effects of structured clinical training on patient and therapist perspectives of alliance early in psychotherapy. Psychotherapy: Theory, Research, Practice, Training, 39, 309-323.

Knox, S. (2003). I sensed you with me the other day: A review of the theoretical and empirical literature on clients' internal representations of therapists. The Psychotherapy Bulletin, 38(2), 2-5.

Knox, S., Caperton, W., Phelps, D. \& Pruitt, N. (2014). A qualitative study of supervisees' internal representations of supervisors. Counselling Psychology Quarterly, 27, 334-352.

Loewald, H. W (1962). Internalization, separation, mourning and the superego. Psychoanalytic Quarterly, 31, 483-504.

Loewald, H. W. (1988). Termination analyzable and unanalyzable. In A. J. Solnit, P. B. Neubauer, S. Abrams, \& A. S. Dowling (Eds.), Psychoanalytic Study of the Child (Vol. 43, pp. 155-166). New Haven, CT: Yale University Press.

Meissner, W. W. (1981). Internalization in psychoanalysis. Madison, CT: International Universities Press.

Orlinsky, D. E., Geller, J.D., Tarragona, M., \& Farber, B. (1993). Patients' representations of psychotherapy: A new focus for psychodynamic research. Journal of Consulting and Clinical Psychology, 61, 596-610.

Safran, J. D. Muran, J. C., \& Eubancks-Carter, C. (2011). Repairing alliance ruptures. Psychotherapy, 48, 80-87.

Watkins, C. E. (2018). The supervisor's internal supervisor representation: Their role in stimulating psychotherapist development. International Journal of Psychotherapy, 22(3), 63-73.

Winnicott, D. W. (1965). The Maturational Processes and the Facilitating Environment. Madison, CT: International Universities Press. 